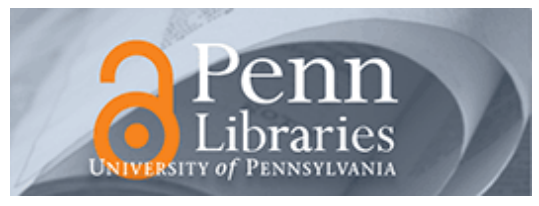

University of Pennsylvania ScholarlyCommons

August 1984

\title{
Scooping the Voters? The Consequences of the Networks' Early Call of the 1980 Presidential Race
}

Michael X. Delli Carpini

University of Pennsylvania, dean@asc.upenn.edu

Follow this and additional works at: https://repository.upenn.edu/asc_papers

\section{Recommended Citation}

Delli Carpini, M. X. (1984). Scooping the Voters? The Consequences of the Networks' Early Call of the 1980 Presidential Race. The Journal of Politics, 46 (3), 866-885. https://doi.org/10.2307/2130859

NOTE: At the time of publication, the author Michael X. Delli Carpini was affiliated with Rutgers University. Currently January 2008, he is a faculty member of the Annenberg School for Communication at the University of Pennsylvania.

This paper is posted at ScholarlyCommons. https://repository.upenn.edu/asc_papers/19

For more information, please contact repository@pobox.upenn.edu. 


\title{
Scooping the Voters? The Consequences of the Networks' Early Call of the 1980 Presidential Race
}

\author{
Abstract \\ The election projection of the 1980 presidential contest by NBC raised much speculation concerning its \\ possible impact on voting in states where the polls were still open. Research on the subject has started \\ from different assumptions, used different data and methods, and come to different conclusions \\ concerning the real-world effects of such early calls. Using district-level voting and demographic data and \\ focusing on deviations from normal voting patterns, this study finds the early call to have had a small but \\ measurable impact on presidential and congressional turnout, and a somewhat larger impact on \\ depressing the vote for Democratic candidates at both levels. In addition, higher income, white collar, and \\ better educated populations appear to have been affected to a greater extent. While the overall impact \\ was too small to have affected the outcome of the presidential race, at the congressional level as many \\ as fourteen races were won by margins smaller than the estimated impact of the early call in those \\ districts.
}

\section{Comments}

NOTE: At the time of publication, the author Michael X. Delli Carpini was affiliated with Rutgers University. Currently January 2008, he is a faculty member of the Annenberg School for Communication at the University of Pennsylvania. 


\title{
Scooping the Voters? The Consequences of the Networks' Early Call of the 1980 Presidential Race
}

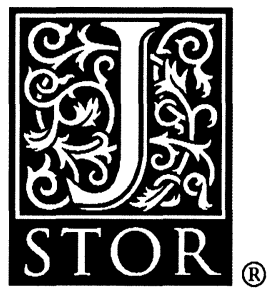

\author{
Michael X. Delli Carpini \\ The Journal of Politics, Vol. 46, No. 3 (Aug., 1984), 866-885.
}

Stable URL:

http://links.jstor.org/sici?sici=0022-3816\%28198408\%2946\%3A3\%3C866\%3ASTVTCO\%3E2.0.CO\%3B2-Y

The Journal of Politics is currently published by Southern Political Science Association.

Your use of the JSTOR archive indicates your acceptance of JSTOR's Terms and Conditions of Use, available at http://www.jstor.org/about/terms.html. JSTOR's Terms and Conditions of Use provides, in part, that unless you have obtained prior permission, you may not download an entire issue of a journal or multiple copies of articles, and you may use content in the JSTOR archive only for your personal, non-commercial use.

Please contact the publisher regarding any further use of this work. Publisher contact information may be obtained at http://www.jstor.org/journals/spsa.html.

Each copy of any part of a JSTOR transmission must contain the same copyright notice that appears on the screen or printed page of such transmission.

JSTOR is an independent not-for-profit organization dedicated to creating and preserving a digital archive of scholarly journals. For more information regarding JSTOR, please contact support@jstor.org. 


\title{
Scooping the Voters? The Consequences of the Networks' Early Call of the 1980 Presidential Race
}

\author{
Michael X. Delli Carpini \\ Rutgers University
}

The election projection of the 1980 presidential contest by NBC raised much speculation concerning its possible impact on voting in states where the polls were still open. Research on the subject has started from different assumptions, used different data and methods, and come to different conclusions concerning the real-world effects of such early calls. Using district-level voting and demographic data and focusing on deviations from normal voting patterns, this study finds the early call to have had a small but measurable impact on presidential and congressional turnout, and a somewhat larger impact on depressing the vote for Democratic candidates at both levels. In addition, higher income, white collar, and better educated populations appear to have been affected to a greater extent. While the overall impact was too small to have affected the outcome of the presidential race, at the congressional level as many as fourteen races were won by margins smaller than the estimated impact of the early call in those districts.

\section{INTRODUCTION}

\section{W}

hile most of the political excitement generated by the 1980 election centered on the surprising gains made by the Republican party, a not inconsiderable controversy arose concerning the impact, if any, of the early prediction of a winner in the presidential race by the television networks. Shortly after 8 o'clock Eastern Standard Time NBC announced that, according to their analysis of exit poll data, Ronald Reagan was to be the next president of the United States. The controversy over that early call

* This research was supported by a grant from the Research Council of Rutgers University and by funds provided by the Eagleton Institute of Politics. I would like to thank C. Anthony Broh, Samuel Kirkpatrick, Jane Whittaker, and the editors and anonymous reviewers of the Journal of Politics for their assistance on earlier versions of this paper. 
was due to the fact that the polls in many states were still open at the time, and in some of the western states would remain open for several hours.

The question, then, was: did the early call affect voting patterns in these states? The debate over the real and potential effects of the early call took place at several levels: disgruntled congressional losers blamed their losses, directly and indirectly, on the prognostication; legislators introduced bills to regulate either poll closing times or the timing of network election predictions; a congressional task force report was released; and journalists and editorialists gave their thoughts on the possible impact of the call.

In addition to this general furor, several researchers have also attempted systematically to uncover the possible effects of such early calls (Wolfinger and Linquiti, 1981; Epstein and Strom, 1981; Jackson, 1983; Tannenbaum and Kostrich, 1983; Dubois, 1983). These studies, starting from different theoretical assumptions and using different data and methods, have come to quite different conclusions, ranging from no effect (Epstein and Strom) to a potential decline of 6 to 12 percent (Jackson).

In this paper we add yet another voice to the debate by analyzing the issue from a somewhat different and, we hope, more conclusive perspective. In order to do this we first lay out the basic issues involved, the substantive and methodological differences among the various approaches to studying the impact, and a justification for the approach taken in this analysis. Next the data and methods to be used are discussed in more detail. Third, the results of the analysis are presented, and finally their significance and implications are considered.

\section{Turnout, Vote Choice, and the Early Call}

There are four key issues in early call controversies: first, is turnout depressed in those areas where the polls were still open? second, are particular types of voters more or less likely to be affected by the call? third, are particular types of candidates more or less likely to suffer from the early call? and, most critical, are the outcomes of particular races affected? As with most important and complex issues, there are good theoretical reasons to expect all or none of these to occur.

The logic of depressed turnout is, of course, that once the presidential race has been decided, some percentage of those who have not yet voted and who still have an opportunity to do so may decide not to vote. As Wolfinger and Linquiti put it:

there is no escaping the fact that it takes the excitement of a presidential race to get many people to the polls. Therefore it seems reasonable to expect that some people who otherwise would have gone to the polls, and voted for non-presidential candidates, choose instead to forego voting when the top draw is no longer in doubt. (1981, p. 56) 
This argument, while having a certain intuitive appeal, is not universally accepted however. Epstein and Strom, for example, argue that "the decision to vote - on the West Coast or anywhere else - is the result of a complicated combination of factors, none of which is related to information received on election day" (p. 486).

The early call need not affect all voters who have yet to vote (but who still have a chance), nor need it affect them all in the same way. Wolfinger and Linquiti, for instance, examine the effect of the early call on individuals with different education levels and different occupations; they assume that socioeconomic status, since it affects both turnout and media use, might interact with the early call. Jackson, on the other hand, examines the interaction between the early call and partisanship, assuming that one's partisan leanings might mute or accentuate any effect.

While a drop in overall turnout is the most obvious impact to expect from an early call, it is also possible that specific vote choices might also be affected. Tannenbaum and Kostrich suggest that a "bandwagon effect" and an "underdog effect" are theoretically plausible expectations in such situations (1983, pp. 27-28).

The final possible effect concerns the actual outcomes of elections. As Tannenbaum and Kostrich correctly point out, it is implausible to suggest that the early call could have affected the outcome of the 1980 presidential race. It is possible, however, that some combination of lowered turnout, bandwagon, or underdog effects for all or specific segments of the involved population could have helped to determine the outcomes of local races, many of which were decided by extremely small margins.

The differences in expectations are matched by parallel differences in findings. This fact leads one set of scholars, upon reviewing the literature, to conclude that the evidence is "mixed and the jury, ourselves among them, has still to issue a verdict" (Tannenbaum and Kostrich, 1983 , p. 83). The problem in determining where the truth lies is confounded by differences in methodology and data. Wolfinger and Linquiti look at the early call of 1972 , use census survey data, and compare 1972 differences in turnout between California and the other states (excluding four) to 1974 differences between the same groupings. Epstein and Strom look at the 1964, 1972, and the 1980 early calls, use state-level voting statistics, and compare the five westernmost states to thirty-five nonwestern and nonsouthern states over a period of as much as twenty years. Jackson uses the 1980 National Election Study in conjunction with a follow-up telephone survey. Tannenbaum and Kostrich review almost all of the research on the topic, reanalyzing much of it using a more multivariate design. Finally, Dubois reanalyzes Epstein and Strom's data, eliminating absentee ballots (which would have been mailed prior 
to the early call) and using the number of registered voters rather than the number of potential voters as the base.

All of the authors offer reasonable justifications for their particular approaches, and all add a good deal to our understanding of the complexities of the relationships involved. All however have certain weaknesses which contribute to the lack of consensus on the issue. Several of these shortcomings are idiosyncratic to specific studies. While a critique of each piece of research is beyond the scope of this article, the problems revolve centrally around the choice of a baseline against which to evaluate the effects of early calls, the choice of which of the three early call elections $(1964,1972$, or 1980) to study, and the level and unit of analysis employed (see Tannenbaum and Kostrich, 1983, for a detailed critique of extant research in this area).

In addition to such study-specific points, there are also two points which apply to almost all of the research on early calls. First, with the exception of Jackson's study, all use rather crude breakdowns concerning where the effects might occur. While the West Coast states are clearly the most likely to be affected, any state where the polls were still open after the NBC announcement should be considered. By not only excluding many such states from the postcall group, but also including them in the precall group, researchers may have confounded their results to some extent. Second, none of the studies examines the effects of early calls for all four of the theorized impacts (turnout, vote choice, the impact on specific segments of the population, and the impact on other races). Wolfinger and Linquiti examine the interaction of the early call with education and occupation, and Jackson tests for the effects of partisanship, but no one tests for the impact on either the direction of the vote choice or on local election results; they focus almost exclusively on turnout instead (Tannenbaum and Kostrich do discuss these issues, but do not present data on them).

The research design used here is a somewhat more complex but, we feel, more accurate approach to the problem. First, it focuses on 1980 as the best example of an early call with the potential to affect voting behavior, since it was the earliest call and the only one in which the race was perceived to be close as the polls opened.' Second, it uses congressional districts as the unit of analysis, since they are not as aggregated as states or regions and yet they are still not dependent on the memories and honesty of individual survey respondents. Third, the point of com-

\footnotetext{
${ }^{1}$ While the expected closeness of the 1980 race makes it a better choice for studying the effects of an early call, the early concession by Carter is problematic. Our analysis cannot distinguish between the two; consequently, it is possible that some of the impact reported here is the result of that concession. In either case, however, the central issue remains whether the voter has received a message that the election has been decided.
} 
parison is an estimate of normal voting patterns which is based upon an average vote over several elections rather than a comparison to a single election. ${ }^{2}$ Fourth, this analysis includes the entire country rather than selected states or regions, making no a priori assumptions as to which of the postcall districts would necessarily be affected. Fifth, actual poll closing times are used to distinguish precall from postcall districts. This not only allows for a more accurate design, but it helps to eliminate regional effects that might confuse interpretations of findings, since many southern, midwestern, and even some eastern states had polls that remained open for some time after the call was made (see appendix A). ${ }^{3}$ Sixth, this design allows one to examine not only the effects on presidential turnout, but also on congressional turnout, specific vote choice at the presidential and at the congressional level, and the impact of a selected set of demographic characteristics. Finally, it includes an estimate of the possible impact of the early call on the outcomes of the individual congressional races in 1980.

${ }^{2}$ The concept of a normal vote is most often applied to presidential voting patterns. In the following analysis we apply it to congressional voting as well. While nothing inherent in the methodology or the theory prevents this kind of analysis, the specific dynamics of congressional elections might be such as to make the idea of a normal vote unrealistic. For several reasons we feel such analysis is justified however. First, the major source of volatility in congressional turnout and vote choice - the difference between off-year and presidential election patterns - is eliminated by the fact that only presidential election years are included in the normal vote estimation. The long-term pattern of voting in presidential and congressional elections during presidential election years is remarkably similar (Flanigan and Zingale, 1983, p. 12). Second, the actual amount of surge and decline in congressional elections during the period examined was almost identical to that found for presidential voting (less than 0.2 percent difference over the four elections examined), suggesting a similar utility for the normal vote analysis. Third, the standard deviations in the congressional normal vote analysis for the four election years are no larger than those for the presidential analysis, indicating that the individual district scores are no more volatile in the congressional case. Finally, idiosyncratic factors such as personality, incumbency, and the effects of other races are no more prevalent in congressional than in presidential races, and no more prevalent in districts where the polls were still open after the early call than in districts where they had closed.

${ }^{3}$ This is an important consideration since, as pointed out both by Epstein and Strom and by Dubois, different long-term trends in voting behavior can lead to a misinterpretation of differences found in 1980. As a check on this we compared the patterns of deviations from the normal vote from 1968 to 1976 for the precall and the postcall districts. In every measure of change used in this analysis overall patterns were quite similar for both groups over time. In addition, we compared only the West Coast states to the precall and the other postcall districts. While the West Coast districts did show a slightly different pattern of deviation from their normal votes, the differences are not consistently in a direction that would bias the results in a way that would increase the apparent effect of the call, and are never more than 1 percent different than the precall districts. This increases our confidence that the differences found in 1980 are not due to regional differences. 


\section{Data ANd Methods}

The data used for examining the impact of the early call are aggregate voting and demographic statistics. The unit of analysis is the congressional district. Congressional districts were chosen for several reasons. First, since districts are smaller and more numerous than states, analyzing them might uncover effects lost in the more aggregated political unit. Second, demographic data are readily available at the district level, and because districts show much greater variance on these statistics than do states, they are more useful for identifying interrelationships. Finally, since districts are the political units that elect members of Congress, they allow the impact of the early call on specific electoral outcomes to be tested.

The specific district-level statistics collected consist of the following: vote for the Democratic, Republican, and "Other" presidential candidates; vote for the Democratic, Republican, and "Other" congressional candidates; and, the number of registered voters. ${ }^{4}$ The data were collected for the elections of 1968, 1972, 1976, and 1980. Since congressional districts in several states had been redistricted during this period, there was a potential problem of lack of comparability within districts over time - a key part of the analysis to follow. Fortunately, two sources exist which recalculate the votes of past elections along the new district lines. ${ }^{5}$

In addition to the voting statistics, data on demographic characteristics of each district were also collected (Barone, Ujifusa, and Matthews, 1980, 1982). The specific categories, which are listed in appendix B, generally center around income, occupational, and educational distributions. Finally, the exact time at which the polls closed in each of the 435 districts was included (obtained from the New York Times, 4 November).

\footnotetext{
${ }^{4}$ Registered voters are used rather than eligible voters because, as Dubois correctly points out, this method eliminates a source of variance that could not be affected by the early call and so increases our confidence that the changes found can be attributed to that call. That is, since the decision to register was made prior to the early call, since different regions have higher or lower rates of registration, and since nonregistered voters cannot vote regardless of whether they heard the early call, including nonregistered voters in the analysis adds nothing and could confound the decision not to register with the decision not to vote. Unfortunately, the number of registered voters is available by state, but not by district. We therefore use state averages for the districts in each state. This method is admittedly not as sensitive as that of Dubois, but it is better than using the number of eligible voters and is, simply put, the best we can do for a study that is national in scope.

${ }^{5}$ Congressional Quarterly provides a recalculation of the congressional vote in districts in Congressional Districts in the Seventies. The Almanac of American Politics provides a similar recalculation for the presidential vote at the district level, as well as the more recent congressional changes.
} 
The basic approach taken in our analysis is to compare the voting behavior of the districts where the polls were still open after the NBC prediction not only with the districts where the polls were closed but also with the "normal vote" of each district. That is, we compare how the postcall districts in 1980 differ from their normal pattern of voting, compare how the precall districts differ from their normal patterns, and then compare these differences to each other.

In order to perform this kind of analysis, measures of a normal vote and of change in the vote are needed. We have chosen an adaptation of the approach developed by Flanigan and Zingale (1974). This method, which is a modification of analysis of variance, defines the normal vote as the mean vote for each unit of analysis over the whole set of elections under consideration. Surge (or decline) is defined as movement away from this normal vote in a particular election and is operationalized for each district as the vote in a particular election minus the district's normal vote. The overall amount of surge or decline is measured by the difference between the grand mean (the average vote for all districts in all election years) and the election mean (the average vote in a particular election). ${ }^{6}$

The Flanigan and Zingale model is used to estimate the eight particular types of surge and decline used in this analysis. Since, as demonstrated by Flanigan and Zingale, basing one's estimate of change on the vote totals for one party can result in a different pattern than estimates based on the other party's vote share, we estimate change in the vote for Democratic, Republican, and "Other" candidates for president. We repeat this for voting at the congressional level.

\footnotetext{
${ }^{6}$ Normal vote analysis has moved in several different directions since Converse first developed the concept (1966). While a review of the various approaches is beyond the scope of this paper, a few comments are in order. First, while Converse's analysis focuses centrally on the development of normal vote analysis in survey research, he also saw its utility in aggregate research. This aggregate approach is developed by Flanigan and Zingale and is employed in this article. Second, because Converse focuses on individual-level data, his operationalization allows for a consideration of the propensity of various groups (most notably individuals with different levels and directions of partisan attachments) to be influenced by short-term forces in an election. The Flanigan and Zingale approach is much more tied to the actual behavior of the units of analysis under consideration. In short, Converse's model determines the normal vote based on prior expectations of the behavior of certain types of individuals, while Flanigan and Zingale's model does so based upon the prior (and subsequent) behavior of more aggregated units. Both, however, are based upon a common and relatively simple logic: the separation of long-term patterns of voting behavior from short-term deviations in that pattern, both for the nation as a whole and for distinct parts of that whole. While this analysis depends heavily on Flanigan and Zingale's model, it is in part an adaption of it. We examine not only the normal partisan vote, but also the normal turnout rates. For comparison, as well as a more in-depth discussion of the method, see Flanigan and Zingale, 1974.
} 
The measures of surge and decline are used in the comparisons of precall and postcall districts. Since these estimates are based upon the normal voting patterns within each district, a relative difference between the two groups would suggest an impact attributable to the early call. In addition, we can compare the behavior of certain types of districts (based on the demographic data) to see if the impact was greater for particular groups in the population.

\section{Findings}

The results of the analyses concerning overall turnout levels are presented in table 1. A positive number indicates a surge in turnout while a negative number indicates a decline, relative to the normal voting patterns in each district. As can be seen, turnout was down in 1980 for

\section{TABLE 1}

Surge and Decline in Turnout Rates For the 1980 Presidential and Congressional Races

\begin{tabular}{|c|c|c|}
\hline & $\begin{array}{c}\text { Presidential } \\
\text { RACE }\end{array}$ & $\begin{array}{c}\text { CONGRESSIONAL } \\
\text { RACES } \\
\end{array}$ \\
\hline $\begin{array}{l}\text { Total Districts: } \\
\qquad(N=435)\end{array}$ & $-2.7 \% \quad(.3)$ & $-3.8 \% \quad(.6)$ \\
\hline $\begin{array}{l}\text { Precall Districts: } \\
\qquad(N=245)\end{array}$ & $-2.1 \% \quad(.4)$ & $-3.4 \% \quad(.4)$ \\
\hline $\begin{array}{l}\text { Postcall Districts: } \\
\qquad(N=190)\end{array}$ & $-3.2 \% \quad(.4)$ & $-4.4 \% \quad(.6)$ \\
\hline Difference: & $-1.1 \%^{*}$ & $-1.0 \% *$ \\
\hline
\end{tabular}

Note: Percentages are the mean amount of surge or decline in the respective groupings. Figures in parentheses are standard errors.

${ }^{*} p \leq .05$.

the country as a whole, with the drop slightly more noticeable in the postcall districts (about 1.1 percent more decline). Turnout in congressional voting shows a similar pattern, with decline in the postcall districts 1.0 percent greater than in the precall districts. Even if we were to attribute all of this difference to the election night projections (something which is by no means obvious), it would seem that while the early call did have an impact on turnout, that impact was small.

While overall turnout showed a relatively small relationship with the early call, the patterns concerning the specific candidates and party affected are somewhat more suggestive. Table 2 presents the relative surge 
TABLE 2

Surge and Decline in Democratic, Republican, and "Other" Vote in the 1980 Presidential Race

\begin{tabular}{|c|c|c|c|}
\hline & $\begin{array}{c}\text { Democratic } \\
\text { Candidate } \\
\end{array}$ & $\begin{array}{l}\text { REPUBLICAN } \\
\text { Candidate }\end{array}$ & $\begin{array}{c}\text { “OTHER" } \\
\text { CANDIDATES }\end{array}$ \\
\hline $\begin{array}{l}\text { Total Districts: } \\
\qquad(N=435)\end{array}$ & $-2.0 \% \quad(.3)$ & $-1.5 \% \quad(.2)$ & $+1.0 \%$ \\
\hline $\begin{array}{l}\text { Precall Districts: } \\
\qquad(N=245)\end{array}$ & $-.7 \%(.4)$ & $-1.5 \%$ & $+.1 \%(.3)$ \\
\hline $\begin{array}{l}\text { Postcall Districts: } \\
\qquad(N=190)\end{array}$ & $-3.8 \% \quad(.3)$ & $-1.5 \% \quad(.3)$ & $+2.1 \%$ \\
\hline Difference & $-3.1 \%^{*}$ & $0 \%$ & $+2.0 \% *$ \\
\hline
\end{tabular}

Note: Percentages are the mean amount of surge or decline in the respective groupings. Figures in parentheses are standard errors.

${ }^{*} p \leq .05$.

and decline in the vote for Carter, Reagan, and Anderson. ${ }^{7}$ Voting for the Republican candidate was completely unaffected by the early call, with precall and postcall districts varying from their normal patterns in exactly the same amount and direction. The Democratic vote, however, declined 3.1 percent more in the postcall districts than in the precall districts. Because these figures are calculated on the normal voting patterns of each district, the differences are not due to underlying partisan leanings in the various districts. It is, of course, still possible that Carter's appeal just happened to be less in the 190 districts in which polls were still open after the projection of results, but the pattern is at least consistent with the argument that the early call led some people not to vote for a candidate who had already lost.

Table 2 also reveals a difference in voting for third party candidates, with a 2 percent surge in the postcall districts. Once again, this difference could simply be the result of stronger support for Anderson in those districts, but the findings leave open the possibility that some voters, seeing that Carter had lost, felt free to vote for the third party candidate. ${ }^{8}$

${ }^{7}$ While overall voting dropped by 1.1 percent, the shift in party vote was in some cases greater. This is possible because table 2 and table 3 capture deviations in the normal vote which take into account both relative shifts and absolute changes in party vote. That is, the change is the result both of a drop in Democratic vote and an overall drop in rate. The drop of 3.1 percent Democratic vote, the increase of 2.0 percent "Other Vote," and the lack of change in Republican voting leads to a net change of -1.1 percent. This imbalance is accounted for by the absolute drop in turnout of 1.1 percent noted in table 1 .

${ }^{8}$ This is consistent with a notion of not wanting to waste a vote, since Anderson was reported to be fighting to reach the 5 percent mark that would enable him to get federal 
When we turn to voting in the congressional elections, slightly larger differences between the precall and the postcall districts are seen (table 3). Voting for Democratic candidates was, of course, down nationally in 1980 , but once again the relative drop was greater in the districts where the polls were still open after the NBC call than in those where they had closed, with a difference of 2.9 percent. In addition, however, voting for Republican candidates declined in the precall districts while it was up slightly in the postcall districts, with a net advantage of 1.8 percent for the Republican party. When this is combined with the differences in Democratic voting there is a total swing of 4.7 percent in favor of the Republicans in the postcall districts: a swing which could be attributed to the early call. ${ }^{9}$

What does a rise in voting Republican above both normal voting patterns within each district and the pattern found in the precall districts suggest about the individual voter's decision-making calculus? While such speculation is risky, these findings suggest something of a bandwagon effect, in which news of the surprising and overwhelming Reagan/Republican victory led to small numbers of voters in those districts in which the polls were still open deciding to be part of this new "mandate." Results using individual-level data demonstrate overreporting of having voted for the candidate who won, lending support to this kind of interpretation. We can not explain, however, why this effect should occur at the congressional level but not at the presidential level. Possibly the fact that the presidential race was technically over, while the congressional races were yet to be decided was a factor, but this is impossible to confirm at the level of analysis presented here.

A final observation on congressional voting concerns third party candidates. Voting for such candidates showed a slight effect, with a difference of 0.3 percent in favor of third party candidates in the postcall

matching funds. In addition, those people who preferred Anderson, but were planning to vote for Carter or Reagan because of the chance that the election might be determined by the third party vote no longer needed to hold back. However, such speculation concerning individual behavior and motivations can not be conclusively demonstrated from the aggregate data presented in this analysis. We have attempted to avoid this fallacy to a great extent by specifying the parameters of the models used in as much detail as possible, by presenting findings at the aggregate level, and by inferring individual causes of such findings with caution and healthy skepticism. Where we do consider such individual behavior it is to demonstrate that one can suggest plausible scenarios at that level which are consistent with the data presented; it is not to argue that such scenarios have been authenticated.

${ }^{9}$ In this analysis we distinguish candidates only by their party label. Other characteristics, such as incumbency, might also affect the way districts reacted to the early call. While such characteristics would be interesting to examine, they fall beyond the scope of this paper. Not examining them should not bias the results discussed here however, since such candidates and such effects are evenly distributed between pre- and postcall districts. 
TABLE 3

Surge and Decline in Democratic, Republican, and "Other" Vote in the 1980 Congressional Races

\begin{tabular}{lccc}
\hline & $\begin{array}{c}\text { Democratic } \\
\text { Candidates }\end{array}$ & $\begin{array}{c}\text { Republican } \\
\text { Candidates }\end{array}$ & $\begin{array}{c}\text { “OtheR" } \\
\text { Candidates }\end{array}$ \\
\hline $\begin{array}{c}\text { Total Districts: } \\
(N=422)\end{array}$ & $-2.1 \%(.7)$ & $0 \%(.6)$ & $+.2 \% \quad(.5)$ \\
$\begin{array}{c}\text { Precall Districts: } \\
(N=241)\end{array}$ & $-.8 \%(1.1)$ & $-.7 \%(.6)$ & $-.1 \%(.1)$ \\
$\begin{array}{c}\text { Postcall Districts: } \\
(N=181)\end{array}$ & $-3.7 \%(.6)$ & $+1.1 \%(1.7)$ & $+.2 \%(.6)$ \\
Difference & & & \\
\hline
\end{tabular}

Note: Percentages are the mean amount of surge or decline in respective groupings. Figures in parentheses are standard errors.

${ }^{*} p \leq .05$.

districts - a finding consistent with voting at the presidential level. The much smaller effect at the congressional level can be attributed to the absence of a single, visible third party equivalent to Anderson.

To this point we have been comparing all of the precall districts to all of the postcall districts, making no further distinctions. If the early call was responsible for the differences found, then we would expect the impact to be more pronounced in those districts where the polls were open latest. We would not, however, expect the effects to be limited solely to the West Coast. Were the effects so limited, the findings discussed above could be attributed to Reagan's popularity in his home region rather than to the early call. In order to test for this possibility, tables $1-3$ were redone, this time to distinguish between non-West postcall districts and West Coast districts (California, Washington, and Oregon). The results, presented in appendix C, tables 1-3, clearly demonstrate that while the West Coast shows the strongest effects (as would be expected given that their polls were open latest), the effects are not at all limited to that region.

In addition to this categorical analysis, simple regression equations were run, with how long the polls were open after the call as the independent variable and the various surge measures as the dependent variables. ${ }^{10}$ The unstandardized regression coefficients, which show the percentage change in the amount of surge (or decline) for each additional

\footnotetext{
10 For this part of the analysis, all polls closing either at the time of or prior to the NBC call were recorded as $8 \mathrm{PM}$, so that impact refers to the number of hours the polls were open after that time.
} 
hour the polls remained open, are presented in table $4 \mathrm{C}$ (appendix $\mathrm{C}$ ). As can be readily seen, the results are consistent with the conclusions drawn from both pre/post comparisons. In addition, the regression analyses show that how long the polls were open after the call was made is useful in distinguishing the amount of decline and surge which took place. This adds further credence to the argument that the early call did, in fact, have an impact. ${ }^{11}$

Having the opportunity to refrain from voting because the outcome has already been announced does not necessarily mean that an individual will take advantage of that opportunity. Put in the aggregate, it is possible that certain types of districts were more or less affected by the early call. In particular, we were interested in how those characteristics found by other studies to relate to levels of political interest, information, and involvement, and to patterns of media use, would affect levels of surge and decline in the postcall districts. In order to test for this the following method was employed. A measure of socioeconomic status (SES) combining standardized measures of education, income, and occupational levels in each district was developed (see appendix B). In addition, measures for the length of time the polls were open after the early call and for the interaction between SES and this time variable (SES $\times$ Number of minutes the polls remained open after $8 \mathrm{PM}$ ) were developed. Multiple regression equations were then run for all 435 districts, with $\mathrm{SES}$, time, and the interaction term as the independent variables and the eight measures of surge and decline as the dependent variables. Controls for age, race, and the closeness of the presidential and congressional races were also introduced to prevent the confounding of SES effects with related political and social variables and to allow more confident translation of the results to the individual level (Langbein and Lichtman, 1977).

The interaction terms which result from these equations are measures of the combined effects of SES and the early call. These effects are presented in table 4. The numbers are the percent increase in the vote for each standard deviation increase in the interaction of SES and the early call. A negative sign indicates that as SES and the length of time the polls

11 The one finding in the regression analysis which is not consistent with the findings of the pre/post comparisons concerns the relationship between poll closing time and voting for Republican congressional candidates. Voting for Republicans was up slightly in the postcall districts, especially relative to the precall districts. In the regression analysis, however, there is evidence which points to a possible depressing effect of the early call on Republican congressional voting. One possible explanation is that while voting for Republican candidates was up generally in these districts, the election prediction acted to depress the amount of surge which occurred, leading to a negative slope in the regression line. A second or additional possibility is that some type of interaction was taking place, with different districts behaving in quite different ways. 
were open after the call increases, voting (either turnout or a particular choice) decreases, while a positive sign indicates the reverse. If one is willing to accept that the interaction term is a valid measure of the effect of the early call on the relationship between SES and voting then it is clear that districts with different levels of SES did react differently to the early call. In addition, while the relationships are not equally strong, all are significant; taken as a whole they show a distinguishable pattern: the better off, better educated, white collar populations show relative declines in six of the eight relationships presented.

\section{TABLE 4}

The Interaction Effects of SES and the Early Call on Voting in the 1980 Presidential and Congressional Elections

\begin{tabular}{|c|c|c|}
\hline & $\begin{array}{c}\text { Presidential } \\
\text { RACE } \\
\end{array}$ & $\begin{array}{c}\text { CONGRESSIONAL } \\
\text { RACES } \\
\end{array}$ \\
\hline Turnout & $-.55 \%(.21)$ & $-.49 \%(.26)$ \\
\hline $\begin{array}{c}\text { Democratic } \\
\text { Vote }\end{array}$ & $-.21 \%(.16)$ & $-.93 \%(.32)$ \\
\hline $\begin{array}{c}\text { Republican } \\
\text { Vote }\end{array}$ & $-.23 \%(.12)$ & $+.18 \%(.16)$ \\
\hline $\begin{array}{c}\text { "Other" } \\
\text { Vote }\end{array}$ & $-.11 \%(.14)$ & $+.25 \%(.27)$ \\
\hline
\end{tabular}

Note: Percentages are the unstandardized regression coefficients for the interaction term of SES $\times$ length of time the polls were open past the early call. They represent the percent increase or decrease in the vote for each standard deviation in the interaction term. The figures in parentheses are standard errors.

This pattern is consistent with the one found by Wolfinger and Linquiti in the 1972 election. They explain the initially surprising result by pointing out that "before people can be deterred from voting by knowing that the networks have called a winner, they must first hear the news. Who is more likely to hear political news than the best educated?" (p. 59). We

\footnotetext{
A potentially interesting test of whether or not the general patterns uncovered in these regressions are actually the result of the early call is to run the same regressions using only the precall districts. One would expect no such pattern of decline over time between 6 and $8 \mathrm{PM}$. Unfortunately such a test cannot be accurately performed because ten of the twelve states which closed prior to $8 \mathrm{PM}$ are southern states. As Epstein and Strom demonstrate, these states have long-term voting patterns that, when compared to northeastern states, show higher turnout and declining Democratic support. In our analysis this would result in a pattern suggesting that the differences among the poll closing times in the precall districts were having an impact - in fact this is a regional effect. This effect is eliminated in the precall/ postcall analysis however (see note 3 ).
} 
concur with this post hoc theorizing and extend it to include not only the most educated but the white collar, higher income citizen as well. In addition, one might speculate that since members of this segment of the population are most likely to see their votes in "instrumental" terms (i.e., in terms of policy preferences and electoral outcomes), it is also this segment of the population which might be most likely to see a vote for a candidate who has already lost or already won as somewhat noninstrumental.

The two exceptions to this pattern of greater decline for the higher SES districts are in voting for Republican and for "Other" congressional candidates. In both cases the exact opposite relationship is found: the early call increases voting for such candidates among higher SES districts. While we are at a loss to explain the voting for third party candidates, a possible explanation for the Republican vote can be based on the discussion of the overall patterns found for congressional voting. We suggested that the increase in voting for Republican congressional candidates might have been the result of a bandwagon effect, but we were surprised to find no such effect at the presidential level. Distinguishing between the already settled presidential race and the still undecided congressional races, and then acting on that distinction, requires a relatively sophisticated calculation. The results presented in table 4 provide evidence that those individuals who made such a distinction were in fact from a segment of the population capable and likely to do so. An even more elaborate explanation might be that Republican activists (who come disproportionately from the higher SES ranks), aware of the potential effects of an early call on the local races (and perhaps noting actual drops in turnout at the polls), worked to get supporters out in a last minute rush, while the Democrats, less organized as a rule and demoralized by the early call, were not able or less able to do so. Again, this is highly speculative; we know of no evidence to demonstrate that this occurred in such districts, though reports of party organizations using early returns to mobilize voters are fairly common.

The impact of the early call on voting in the presidential election was clearly too small to have affected the outcome in even one state, let alone the race overall. On the congressional level, however, it is theoretically possible that a race could have been close enough to be affected by this kind of "disturbance." Our final analysis is an attempt to determine any indication of whether this is empirically possible. In order to do this one could simply see if any races were closer than the average net amount of surge and decline in congressional voting: this analysis reveals that fourteen races were decided by an amount smaller than the net Republican advantage of 4.7 percent established in table 3 . This approach ignores the differences in the impact of the early call among districts of varying 
demographic characteristics and is, therefore, a relatively crude estimation procedure. In addition, therefore, we also used the basic method of estimating the effects of SES to develop a more sensitive measure of impact. First, a series of demographic and political variables, along with their interaction with poll closing times, were included in a regression equation. ${ }^{12}$ Second, using surge in the vote for Democratic congressional candidates and surge in the vote for Republican congressional candidates as the separate dependent variables, the equation was run for all 435 districts. Third, the resulting unstandardized regression coefficients for the interaction terms were used to estimate the amount of surge and decline in the postcall districts which could be attributed to the early call. Fourth, the surge and/or decline in congressional voting for Republican and Democratic candidates were combined to obtain a measure of the net impact of the early call; and finally, this net impact was compared to the actual margin of victory in the various postcall congressional races to see if any districts had races that were decided by a smaller margin than the estimated impact of the early call.

The average net impact which results from this estimation procedure is a 4.9 percent advantage for the Republican candidates, with a standard error of only 0.51 percent. This is strikingly similar to the 4.7 percent Republican advantage derived from the procedure used earlier in this paper and is, therefore, an encouraging sign that the new estimates are not unrealistic (and that both estimates are relatively valid and reliable). The value of this new estimate, of course, is that it is more finely tuned to specific types of districts. When we compare these estimated impacts to the actual margins of victory, we find that of the 190 postcall races, only five were won by a smaller impact than the estimated effect of the early call in that district. Of these five districts, four are cases in which Republicans won. When we include the standard error into our comparison we find that the total number of districts affected ranges from five to seven, with from four to six races won by the Republicans and from zero to three won by the Democrats. We do not claim in this analysis to have identified the races which were in fact affected: only that it is possible, using a set of realistic assumptions, to argue that some small percentage of the races could have been affected, and that such an effect appears to have been to the Republicans' net advantage. ${ }^{13}$

${ }^{12}$ For the specific variables used, see appendix B. Several interaction terms are used here in a rather inductive approach since the goal of this part of the analysis is to replicate as much of the variance in surge and decline in the postcall districts as possible.

${ }^{13}$ The specific districts involved were examined individually, and the argument of an effect by the early call is plausible in all of them. 


\section{Summary and Conclusion}

In this paper we have tried to shed new light on the debate concerning the early call of the 1980 presidential election by examining the patterns of voting in a different and more illuminating way. The results suggest the following. First, turnout for both the presidential and congressional races was down in the affected districts, but by an amount smaller than that found by Jackson. Our findings on turnout are more in line with those found by Wolfinger and Linquiti in 1972 and Dubois in 1980, especially when only the West Coast is considered. Second, the choice of whom to vote for appears to have been affected to a somewhat greater extent, with voting for the Democratic candidates for Congress and the presidency depressed, voting for third party candidates increased, and voting for Republican candidates giving mixed indications leaning toward a type of bandwagon effect. Third, consistent with the argument that the early call was responsible for these deviations from past behavior, the impact was greater the later the polls were open, but was found even in non-West Coast districts. Fourth, consistent with Wolfinger and Linquiti's research (and contrary to that of Tannenbaum and Kostrich) the greatest impacts were found in those districts whose residents were most likely to follow election results: the more educated, higher income, white collar population. Fifth, it is arguable that the impact of the early call was large enough in some postcall districts to have affected the outcomes of from five to fourteen of the congressional races. Finally, the general pattern of disadvantage for the Democrats holds true for these individual races, in which most were cases of Republicans winning by margins smaller than the estimated impact of the early call.

The results of this analysis are significant at two levels. First, if we are correct, then it would seem that the 1980 pronouncement by NBC did have a small but measurable impact on the results of the elections, and that the consequences of the call go beyond the presidential contest. Second-and in some ways more interesting from an academic standpoint - the results indicate that the media can indeed affect political behavior differentially, when exposure is different. A major problem in media research is finding real-world examples of the media reaching some people but not others. It is, as a rule, such a pervasive element of our society that it is difficult to find a truly unaffected population. The 1980 election provided a natural experiment for testing effects, and the results of our analysis suggest that the impact of the media on political behavior is real, identifiable, and complex.

It is not our intention to argue that the results of this analysis lead to the conclusion that networks should be limited in their freedom to make such early predictions, nor to advocate policies such as uniform poll closing 
times. Since such speculation is inevitable, however, three caveats to this kind of a reaction should be noted. First, because we are working with such small differences in numbers, many other things could be affecting the patterns we have uncovered. It is possible, especially concerning the patterns of vote choice, that the Republicans were simply unusually attractive in those districts that coincidentally closed their polls at a later hour. Perhaps Carter's early concession, while admittedly in part the result of the early call, was a critical magnifier of the impact. It may be that had we chosen a different method of estimation, a somewhat different pattern of impacts would have resulted. Finally, perhaps circumstances unique to the 1980 election make it unlikely that an early call in another year would have the same results. We suspect that all of these things are important in addition to the early call; we are, therefore, more confident in the general directions of the findings than in the specific numbers presented.

Second, even if one accepts at face value these results, it does not automatically follow that something must be done. The decision to vote is the result of a myriad of factors all subject to change in a changing environment. Election and registration laws, education levels, the advent of mass newspapers and the electronic media, changing party structures and campaign strategies, the individual personalities and issues all affect who will vote and for whom: that is simply the nature of voting in a complex society. Our analysis suggests that the networks' early predictions should be added to the list of environmental factors - not that this should necessarily be singled out.

Finally, even if one does conclude that the network predictions are somehow different from other environmental factors and should be controlled for the sake of democratic norms and principles, a host of equally lofty norms and principles concerning freedom of speech and the press remain to complicate the debate - a debate that has no clearly democratic solution.

\section{REFERENCES}

Barone, Michael, Grant Ujifusa, and Douglas Matthews (1968-1982). The Almanac of American Politics. New York: E. P. Dutton.

Congressional Districts in the Seventies (1974). Washington, D.C.: Congressional Quarterly Press.

Converse, Philip E. (1966). "The Concept of the Normal Vote." In A. Campbell et al., Elections and the Political Order. New York: John Wiley and Sons.

Dubois, Philip L. (1983). "Election Night Projections and Voter Turnout in the West." American Politics Quarterly 11: 349-63. 
Epstein, Laurily K., and Gerald Strom (1981). "Election Night Projections and West Coast Turnout." American Politics Quarterly 9: 470-92.

Flanigan, William, and Nancy Zingale (1974). "The Measurement of Electoral Change." Political Methodology 1: 49-82. and Bacon.

(1983). Political Behavior of the American Electorate. 5th ed. Boston: Allyn

Jackson, John (1983). "Election Reporting and Voter Turnout." American Journal of Political Science 27: 615-35.

Langbein, Laura Irwin, and Allan Lichtman (1977). Ecological Inference. Beverly Hills, CA: Sage Publications.

Tannenbaum, Percy H., and Leslie J. Kostrich (1983). Turned-On TV/Turned-Off Voters. Beverly Hills, CA: Sage Publications.

Wolfinger, Raymond, and Peter Linquiti (1981). "Network Election Day Predictions and Western Voters." Public Opinion 3: 56-60.

\section{Appendix A}

Poll Closing Times: All times are Eastern Standard Time. Where a range of times is shown, individual districts were determined by a map indicating time zone changes. When this did not account for the range, the average closing time was used.

$\begin{array}{llll}\text { Alabama } & 6-8 \mathrm{PM} & \text { Montana } & 10 \mathrm{PM} \\ \text { Alaska } & 11 \mathrm{PM}-2 \mathrm{AM} & \text { Nebraska } & 9 \mathrm{PM} \\ \text { Arizona } & 9 \mathrm{PM} & \text { Nevada } & 10 \mathrm{PM} \\ \text { Arkansas } & 8: 30 \mathrm{PM} & \text { New Hampshire } & 6-8 \mathrm{PM} \\ \text { California } & 11 \mathrm{PM} & \text { New Jersey } & 8 \mathrm{PM} \\ \text { Colorado } & 9 \mathrm{PM} & \text { New Mexico } & 9 \mathrm{PM} \\ \text { Connecticut } & 8 \mathrm{PM} & \text { New York } & 9 \mathrm{PM} \\ \text { Delaware } & 8 \mathrm{PM} & \text { North Carolina } & 7: 30-8: 30 \mathrm{PM} \\ \text { Florida } & 7-8 \mathrm{PM} & \text { North Dakota } & 8-9 \mathrm{PM} \\ \text { Georgia } & 7 \mathrm{PM} & \text { Ohio } & 7: 30 \mathrm{PM} \\ \text { Hawaii } & 11 \mathrm{PM} & \text { Oklahoma } & 8 \mathrm{PM} \\ \text { Idaho } & 10-11 \mathrm{PM} & \text { Oregon } & 11 \mathrm{PM} \\ \text { Illinois } & 8 \mathrm{PM} & \text { Pennsylvania } & 8 \mathrm{PM} \\ \text { Indiana } & 6-7 \mathrm{PM} & \text { Rhode Island } & 9 \mathrm{PM} \\ \text { Iowa } & 10 \mathrm{PM} & \text { South Carolina } & 7 \mathrm{PM} \\ \text { Kansas } & 9-10 \mathrm{PM} & \text { South Dakota } & 8-9 \mathrm{PM} \\ \text { Kentucky } & 6-7 \mathrm{PM} & \text { Tennessee } & 8 \mathrm{PM} \\ \text { Louisiana } & 9 \mathrm{PM} & \text { Texas } & 8-9 \mathrm{PM} \\ \text { Maine } & 8-9 \mathrm{PM} & \text { Utah } & 10 \mathrm{PM} \\ \text { Maryland } & 8 \mathrm{PM} & \text { Vermont } & 7 \mathrm{PM} \\ \text { Massachusetts } & 8 \mathrm{PM} & \text { Virginia } & 7 \mathrm{PM}\end{array}$




$\begin{array}{llll}\text { Michigan } & \text { 8-9 PM } & \text { Washington } & \text { 11 PM } \\ \text { Minnesota } & 9 \text { PM } & \text { West Virginia } & 7: 30 \text { PM } \\ \text { Mississippi } & 7 \text { PM } & \text { Wisconsin } & 9 \text { PM } \\ \text { Missouri } & 8 \mathrm{PM} & \text { Wyoming } & 9 \text { PM }\end{array}$

Precall Districts: 245

Postcall Districts: 190

\section{Appendix B \\ Demographic Variables Used for Estimating \\ THE IMPACT OF THE EARLy Call}

1. 'Percent earning $\$ 15,000$ or more. ${ }^{*}$

2. Median education level.*

3. Percent white collar.*

4. Median age.
5. Percent black.

6. Closeness of the presidential vote.

7. Closeness of the congressional vote.

8. Number of minutes the polls remained open after eight PM.

* Standardized and combined into a single measure of SES.

Appendix C

Surge and Decline Comparisons Distinguishing between West Coast and Non-West Coast Postcall Distructs

TABLE 1C

Surge and Decline in Turnout Rates for the 1980 Presidential and Congressional Races

\begin{tabular}{|c|c|c|}
\hline & $\begin{array}{c}\text { Presidential } \\
\text { RACE } \\
\end{array}$ & $\begin{array}{c}\text { CONGRESSIONAL } \\
\text { RACES } \\
\end{array}$ \\
\hline $\begin{array}{l}\text { Precall Districts: } \\
\qquad(N=245)\end{array}$ & $-2.1 \% \quad(.4)$ & $-3.4 \% \quad(.4)$ \\
\hline $\begin{array}{l}\text { Postcall Districts: } \\
\text { Without West Coast } \\
\qquad(N=136)\end{array}$ & $-2.9 \% \quad(.6)$ & $-3.8 \% \quad(.6)$ \\
\hline West Coast Districts: ${ }^{a}$ & $-4.2 \% \quad(.6)$ & $-5.6 \%(.9)$ \\
\hline
\end{tabular}

Note: Percentages are mean amount of surge or decline in the respective groupings. Figures in parentheses are standard errors.

"California, Oregon, and Washington. 
TABLE 2C

Surge and Decline in Democratic, Republican, and "Other" Vote in the 1980 Presidential Race

\begin{tabular}{|c|c|c|c|}
\hline & $\begin{array}{c}\text { Democratic } \\
\text { Candidate } \\
\end{array}$ & $\begin{array}{c}\text { RePUblican } \\
\text { Candidate } \\
\end{array}$ & $\begin{array}{c}\text { "Other" } \\
\text { Candidates }\end{array}$ \\
\hline $\begin{array}{l}\text { Precall Districts: } \\
\qquad(N=245)\end{array}$ & $-.7 \%(.4)$ & $-1.5 \% \quad(.3)$ & $+.1 \%(.3)$ \\
\hline $\begin{array}{l}\text { Postcall Districts: } \\
\text { Without West Coast } \\
\qquad(N=136)\end{array}$ & $-2.9 \% \quad(.4)$ & $-1.4 \% \quad(.4)$ & $+1.5 \%$ \\
\hline $\begin{array}{l}\text { West Coast Districts: }{ }^{a} \\
\qquad(N=54)\end{array}$ & $-6.2 \% \quad(.3)$ & $-1.8 \% \quad(.4)$ & $+3.7 \% \quad(.3)$ \\
\hline
\end{tabular}

Note: Percentages are mean amount of surge or decline in the respective groupings. Figures in parentheses are standard errors.

a California, Oregon, and Washington.

TABLE 3C

Surge and Decline in Democratic, Republican, and "Other" Vote IN THE 1980 CONGRessional RACES

\begin{tabular}{|c|c|c|c|}
\hline & $\begin{array}{l}\text { Democratic } \\
\text { Candidates }\end{array}$ & $\begin{array}{l}\text { REPUBLICAN } \\
\text { CANDIDATES } \\
\end{array}$ & $\begin{array}{c}\text { “Other" } \\
\text { Candidates }\end{array}$ \\
\hline $\begin{array}{l}\text { Precall Districts: } \\
\qquad(N=241)\end{array}$ & $-.9 \%(.9)$ & $-.7 \%(.6)$ & $-.1 \%(.2)$ \\
\hline $\begin{array}{l}\text { Postcall Districts: } \\
\text { Without West Coast } \\
\qquad(N=128)\end{array}$ & $-3.2 \% \quad(.7)$ & $+2.1 \% \quad(2.3)$ & $+1.4 \% \quad(2.0)$ \\
\hline West Coast Districts: ${ }^{a}$ & $-4.6 \% \quad(1.0)$ & $-1.3 \% \quad(1.3)$ & $0.0 \% \quad(.1)$ \\
\hline
\end{tabular}

Note: Percentages are mean amount of surge or decline in the respective groupings. Figures in parentheses are standard errors.

California, Oregon, and Washington.

TABLE 4C

Rate of Surge and Decline in Presidential and Congressional Voting Per Hour That the Polls Remained Open

\begin{tabular}{lrrr}
\hline & Presidential Vote & Congressional Vote \\
\hline Overall Turnout: & $-.63 \%$ & $(.3)$ & $-.87 \%(.3)$ \\
Democratic Vote: & $-2.00 \%(.3)$ & $-1.20 \%(.6)$ \\
Republican Vote: & $-.10 \%(.2)$ & $-.52 \%(.8)$ \\
"Other" Vote: & $+1.40 \%(.2)$ & $+.27 \%(.7)$ \\
$N=$ & 435 & 422 \\
\hline
\end{tabular}

Note: Percentages are unstandardized regression coefficients. Figures in parentheses are standard errors. 